\title{
Expediting Return to Work Full Duty with Successful Onsite Medical Management
}

\author{
Kathy Norris PT,CEAS,COMT * \\ Emory Healthcare, USA \\ Submission: July 09, 2017; Published: July 21, 2017 \\ *Corresponding author: Kathy Norris PT,CEAS,COMT, Emory Healthcare, 1364 Clifton Rd.NE, Atlanta, GA 30341, USA, \\ Email: kathy.forde@emoryhealthcare.org
}

\begin{abstract}
Emory Healthcare with Emory University in Atlanta, Georgia is the largest employer in DeKalb County with 39,075 employees. Originally, the Employee Health Department handled all work related injuries. Contract onsite physical therapy and ergonomic services were added in 2001. Emory employees with work related musculoskeletal injures were discharged after five onsite physical therapy visits on average versus the national average of fourteen outpatient visits. With the cost of physical therapy and labor costs only, the estimated cost savings was $\$ 887,574$ in 2006. In 2008, Emory's Occupational Injury Management Department separated from the Employee Health Department to handle injured employees. Two orthopedic physical therapists specializing in ergonomics were hired full time. Emory's Occupational Injury Management Department consists of a medical director, nurse practitioners, case managers, physical therapists, and a safe patient handling coordinator. At Emory, an injured employee fills out an online incident report and is seen by the medical staff within 1 to 48 hours. If physical therapy is indicated, the employee is scheduled. The employee is evaluated in physical therapy, treated and instructed in proper body mechanics. An ergonomic evaluation is performed if an employee has symptoms due to the work postures or the physical demands of the job. Physical therapy statistics of discharged patients were recorded for three years to evaluate the work status on discharge, number of physical therapy visits, the departments where injuries occurred, types of injuries and the body parts injured. The goal was to provide good evidence based justification for an onsite medical team model with physical therapy and ergonomic services. The information was utilized to target the common injuries and develop a plan to reduce and prevent further injuries. Between 312 to 342 Emory employees were discharged annually from onsite physical therapy. The statistics consistently revealed $90 \%$ to $93 \%$ of the employees returned to work full duty. With close medical management, only $35 \%$ of the employees required referral to an outside physician. The primary departments where injuries occurred were in Nursing, Facilities Management, and the Food and Nutrition Departments. Injury prevention programs were designed for these departments based on the ergonomic evaluations. The Safe Patient Handling Program was initiated in 2006. Overhead and mobile lifts were utilized in the patient rooms. With continual nursing education and administrative support, there has been a $12.5 \%$ cumulative reduction in lifting injuries in 2014. In 2005, the average cost per WC case was $\$ 3500$ but currently is $\$ 1400$. Emory's comprehensive approach has proven to expedite the successful return to full duty work and significantly reduce the cost of work related injuries.
\end{abstract}

Keywords: Emory occupational injury management team; Onsite medical management; Onsite physical therapy; Ergonomic

Evolution of the Occupational Injury Management Team

Returning an injured worker to full duty work is challenging. In October 2012, according to the U.S. Department of Labor, healthcare workers experienced musculoskeletal disorders at a rate that exceeds workers in construction, mining and manufacturing. The injuries are mostly associated with repositioning patients in bed. The injury incidence rate per 10,000 employees is over 600 full time workers in healthcare versus just under 200 workers in construction [1].

In March 2015, Emory Healthcare along with Emory University in Atlanta, Georgia continues to be the largest employer in DeKalb County with 39,075 employees. Currently, Emory Healthcare has five hospitals and multiple clinics in the metropolitan area. Our employee base increased from 20,000 employees to 29,500 employees in 10 years. Originally in 2000 , the Employee Health Department handled all work related injuries. The Employee Health Department experienced difficulties tracking employees with work related musculoskeletal injures. In 2001, contract onsite physical therapy and ergonomic services were added on a trial basis to expedite treating musculoskeletal injuries. The Emory Employee Health Department provided the physical therapy space in three locations in close proximity to the Employee Health locations. 
Between 2000 to 2008, it was determined that when an employee was treated onsite for physical therapy, they were generally seen for 45 minutes to 60 minutes with minimal travel time to and from their work location. However, when an employee was seen at an outpatient physical therapy center off site, the time away from work could be two hours or more. Monthly statistics were recorded and compared to the national average number of physical therapy treatments required till discharge from care. Emory employees treated onsite were discharged on average after five onsite physical therapy visits versus the national average of fourteen visits at an outpatient physical therapy clinic [2].

Originally, the Employee Health Department had two divisions in the office, one area handled work related injuries and one area performed new hire and employee annual physicals. The worker compensation staff had nurse practitioners and two case managers. In 2008, Emory's Occupational Injury Management Department separated from underneath the Employee Health Department umbrella to solely handle Emory Healthcare's work related injuries. Two physical therapists that specialized in orthopedics and ergonomics were hired as full time employees. Today the Emory Occupational Injury Management Department consists of one medical director, seven nurse practitioners, four case managers, two physical therapists, a safe patient handling coordinator, a blood borne pathogen coordinator and three administrative assistants. The keys to success are expediting treatment of the employee, close communication with the Occupational Injury Management Medical Team and ergonomic intervention.

\section{Expediting Treatment for a Work Related Injury}

In general when an employee is injured on the job, getting them into a physician or Occupational Medicine Clinic can take several hours to a week. Prior to the formation of Emory's Occupational Injury Management Department, when an Emory employee was injured, the employee would fill out an incident report paper form. This would be filled out directly in the department or faxed in from the location. In 2008, in an effort to expedite the reporting and treatment of work related injuries, a STARS online reporting form was created and implemented. At Emory Healthcare, an injured employee fills out an online incident report and is set up with an appointment to see a nurse practitioner in one hour to 48 hours. If physical therapy is indicated, the employee is scheduled within one hour from being seen in the clinic to 48 hours. The nurse practitioners will coordinate the return to work status with the supervisors. The employee will be returned to work with a light duty or a full duty release as the situation presents. If there is no light duty available within the department, the injured worker will have to go out on medical leave until a full duty released is granted. The employee will come in for regular follow-ups within two days to every two weeks as symptoms indicate with the treatment plan.
If the employee continues to have symptoms that do not fully resolve with the current treatment, the employee may see the medical director or they will choose a panel physician of their choice. The employee is then transferred to the care of a nurse case manager who will coordinate every aspect of their case. This will include scheduling physician appointments, arranging special tests and assisting with workers' compensation pay if they are out of work. Though the nurse case manager tries to get the employee into the physician as soon as possible, it may still take two weeks or more to get an appointment with the specialty physician. The employee will continue to be followed by the nurse practitioner as needed until the panel physician can see the employee.

\section{Onsite Physical Therapy and Ergonomics}

If an Emory employee with a musculoskeletal injury requires physical therapy, they are referred directly from the nurse practitioner's office. Many times, they can be seen the same day. The employee is evaluated in physical therapy, receives treatment and is instructed in proper body mechanics. If an employee has symptoms due to the work postures or physical demands of the job, the physical therapist will perform an ergonomic analysis. If a specific trend of injures is detected, the physical therapist will perform an ergonomic analysis in the designated department. Ergonomic assessment has been very beneficial in minimizing stressful postures on the job and expediting recovery from injury.

At Emory Healthcare, a workstation evaluation is frequently performed. The evaluation assesses the employee hours on the job, work duties, history of the employee's injury, and risk factors are identified. Recommendations are then given to eliminate the risk factors. Initially when the ergonomic program started at Emory Healthcare, detailed work task analyses were performed. The work task analysis details the specific physical job demands per task, and existing environmental factors per job title. This has assisted in helping to update the physical job demands level per job titles within the Emory Healthcare departments. Ergonomic interventions were given to help prevent further work related injuries. As needed, a Fit for Duty Test is designed based on the work task analysis. Employees are tested to assess their capability to return to work full duty.

\section{Statistical Outcomes with Onsite Physical Therapy and Ergonomics}

In 2008, two physical therapists were hired directly to work for the Emory Occupational Injury Management Department. Physical therapy statistics of discharged Emory employees were recorded for three years from 2008 to 2011. The goal was to provide good evidence based justification for the onsite medical management team model with physical therapy and ergonomic services. Statistics were gathered and assessed utilizing an Apple Numbers '09 software program. The study included 
the employee's work status on discharge, the total number of physical therapy visits, the departments where the injuries occurred, the types of injuries and the body parts injured. The study also included the number of employees who were referred to a specialty physician. The information was utilized to assess the injury trends and to develop a plan to reduce the overall injuries.

Table 1: Location of Work Related Injuries 2008 to 2009.

\begin{tabular}{|c|c|c|}
\hline Department & \# Employees & \% Injury \\
\hline Nursing & 128 & $39 \%$ \\
\hline Facilities Management & 31 & $9 \%$ \\
\hline Food \& Nutrition & 27 & $8 \%$ \\
\hline Animal Care Facility & 18 & $5 \%$ \\
\hline Emory University & 19 & $6 \%$ \\
\hline Radiology & 12 & $4 \%$ \\
\hline Environmental Services & 13 & $4 \%$ \\
\hline Miscellaneous EUH & 35 & $11 \%$ \\
\hline Winship Cancer Center & 10 & $3 \%$ \\
\hline Other Hospitals & 18 & $5 \%$ \\
\hline Clinics & 9 & $3 \%$ \\
\hline Clinical Lab & 8 & $3 \%$ \\
\hline
\end{tabular}

Table 2: Mechanisms of Injuries 2008 to 2009.

\begin{tabular}{|c|c|c|}
\hline Injury Type & \# Of Injuries & \% Injury \\
\hline Lifting & 135 & $41 \%$ \\
\hline Falls & 73 & $22 \%$ \\
\hline Trauma & 49 & $15 \%$ \\
\hline Gradual Onset & 30 & $9 \%$ \\
\hline Pulling & 22 & $7 \%$ \\
\hline Pushing & 8 & $2 \%$ \\
\hline Pull/Push & 3 & $1 \%$ \\
\hline Bending & 2 & $1 \%$ \\
\hline Reaching & 2 & $1 \%$ \\
\hline Squatting & 1 & $<1 \%$ \\
\hline Repetitive & 1 & $<1 \%$ \\
\hline
\end{tabular}

During the three-year study, between 312 to 342 Emory employees were discharged annually from onsite physical therapy. The statistics consistently revealed $90 \%$ to $93 \%$ of the employees returned to work full duty. As to be expected, the primary departments where injuries occurred were in the Nursing Department 39\%, Facilities Management 9\%, and the Food and Nutrition Department 8\% (Table 1). The primary mechanisms of injury were lifting, 41\%, and falls, $22 \%$ (Table 2). Back injuries accounted for $42 \%$ of the areas injured with shoulder injuries the next highest at $18 \%$. In 2008, 59\% of Emory employees on average only required five visits or less for physical therapy and then in 2009, 64\% were discharged after five visits or less. About a fourth of the employees, 24\%, required six to ten physical therapy visits before discharge from care. Injury prevention programs were designed specifically for these departments based on the ergonomic information from the job tasks and targeted risk reduction for these departments. Lifting injuries reduced from 135 employees, 41\%, to only 113 employees, $34 \%$, from 2008 to 2010 . With close internal medical management, only $35 \%$ of the Emory employees required referral to an outside physician.

\section{Cost Savings with Onsite Medical Management}

Emory Healthcare along with Emory University employed 20,000 staff members in 2004 and increased to 30,000 employees by 2013. The Emory Occupational Injury Management Department was officially established in 2008 with a team of nurse practitioners, nurse case managers and physical therapists. In March 2015, Emory Healthcare has five hospitals and multiple clinics in the metropolitan area with 39,075 employees. According to the National Academy of Social Insurance in 2013, employer's costs for work related injuries have increased $7 \%$ since 2010 due to increased employment and wages [3]. Direct and indirect costs associated with back injuries in the healthcare industry are estimated to be $\$ 20$ billion annually [4]. With onsite medical management with a team of nurse practitioners, nurse case managers and onsite physical therapy, our medical costs have reduced from 4.26 million dollars with 20,000 employees in 2004 to 3.637 million dollars with 30,000 employees in 2013 (Figure 1).

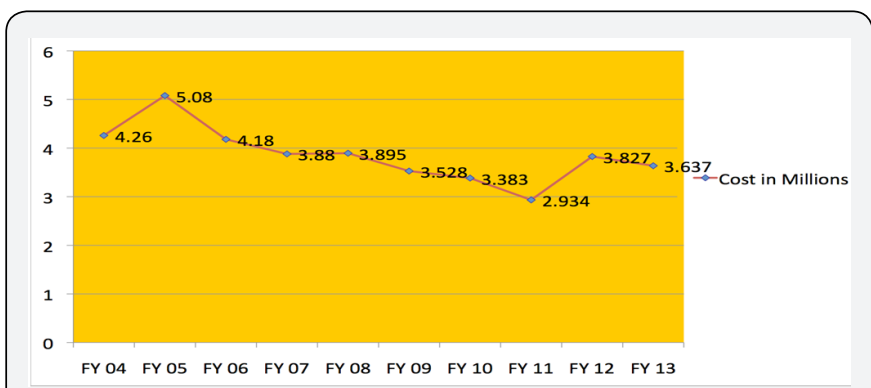

Figure 1: Emory Cost Savings Trend with 20,000 Employees in 2004 vs. 30,000 employees in 2013.

When an employee is injured, getting them into a physician or Occupation Medicine Clinic can take hours to a week. If an employee has to be out of work during this time, it can take longer to return them back to work full duty. Henry Intili, FNP with the Emory's Occupational Injury Management Department, performed a study looking at the comparison of Workers Compensation treatment costs with the nurse practitioner versus a panel physician. The study included the cost for initial evaluation and treatment, medicine costs, physical therapy and transportation. Between January 2008 and May 2008, the average cost per employee for 76 cases treated by the nurse practitioner was $\$ 423.00$. The same treatment for 22 patients with the same acuity by a panel physician had an average cost of $\$ 1531$. For treatment of 76 employees onsite only, the cost savings is over $\$ 84,200$ [5]. From 2008 to 2009 , the physical therapy yearly 
statistics showed that with 333 employees referred for onsite physical therapy treatment, only 115 employees, 35\%, had to be referred to panel physicians. This is a cost savings of $\$ 239,582$.

In 2006, 467 Emory employees were treated with onsite physical therapy and discharged after an average of 5 physical therapy visits. The average cost of a session was $\$ 109.22$. The average cost for an employee treated with onsite physical therapy was $\$ 546.33$ versus $\$ 1594.61$ for 14.5 visits per case when seen off site. If the average employee's wage is $\$ 12.00$ per hour, the yearly cost of lost wages due to time away for physical therapy for 467 employees, is $\$ 238,170$ vs. $\$ 949,230$ if this employee was seen off site. With the cost of physical therapy treatment and labor costs only, the estimated cost savings was $\$ 887,574$ in 2006 alone. In general, treating an employee with onsite physical therapy costs two thirds less versus outside referral for physical therapy.

\section{The Safe Patient Handling Program}

The Safe Patient Handling Program was initiated in 2006. A safe patient handling coordinator was hired. Due to the high injury rate with the nursing staff, an ergonomic study was conducted in 2006. A plan was devised to install the overhead Like Lifts in the ICUs, and purchase the mobile Sabina and Viking Liko Lifts. teams were to be established. With the down turn in the economy in 2007, Emory Healthcare invested in the equipment to reduce the physical stress of the nursing staff but deferred hiring a lift team. Overhead lifts and mobile lifts were utilized in the patient rooms and in some clinic settings i.e. radiology. In 2010 to 2011, the physical therapy statistics revealed that $23 \%$ of the Emory work related injuries were due to patient handling. Initially it was challenging to keep a sufficient supply of the lift sheets and to have the nursing staff consistently utilize the lift equipment. With significant continual staff education and strong nursing administrative support, there has been a $12.5 \%$ cumulative reduction in injuries in 2014 with the Safe Patient Handling Program. Other ancillary departments, such as Radiology, have been instructed in the use of the lifts as well.

\section{Proactive Injury Prevention Programs}

Ergonomic evaluations were performed at Emory Healthcare and Emory University to identify interventions needed to eliminate risk factors that lead to musculoskeletal injuries. Detailed work task analyses were performed in areas where there was a trend for injury. The physical therapy staff designed injury prevention programs specifically for departments in the areas of high risk. Pictures and data from force gauge measurements were utilized in PowerPoint Presentations to allow the staff to see the physical stress of the job and see ways to work smarter, not harder. The physical therapy statistics showed a trend of lifting injuries with the nursing department. The primary body parts injured were the back, shoulder and wrists. An injury prevention program was created to show ways to reduce the injuries with neutral hand and back positioning with lifting. Lifting injuries reduced from $41 \%$ to $34 \%$, from the first year in 2008 to the second year in 2009 . The injury prevention programs are interactive to help the staff learn by hearing, seeing and performing lifting activities and stretches. The injury prevention programs emphasize proper posture, body mechanics and on the job stretches to reduce stressful posture.

\section{Conclusion}

Health care workers have one of the highest injury rates due to the heavy lifting demands on the medical staff. The trend at Emory Healthcare is a higher acuity patient population that requires a greater level of care. NIOSH reports healthcare is the fastest-growing sector of the U.S. economy, employing over 18 million workers. Women represent nearly $80 \%$ of the healthcare work force [4]. With a growing and aging employee base, costs savings and keeping a healthy work force is imperative. Emory's comprehensive onsite medical management approach expedites the successful return to full duty work and significantly reduces the cost of work related injuries.

Emory Healthcare has been voted as one of the top places to work in Atlanta multiple years in a row by the Atlanta Journal Constitution survey. Selection is based solely on employee feedback in an effort to make the list an authentic representation of the work environments of the organizations included in the metro Atlanta area [6]. Emory is invested in taking care of their internal customers, their employees. By expediting medical care for employees injured on the job in the Emory Occupational Injury Management Department, the employees are able to recuperate faster and successfully return to work full duty. Our goals are to teach the employees to utilizes good body mechanics, perform regular on the job stretches and always work smarter not harder. At Emory, we are all in this together to create a healthy work environment.

\section{References}

1. Department of Health and Human Services (2013) Preventing Back Injuries in Healthcare Settings. Centers for Disease Control and Prevention- NIOSH Science Blog.

2. Argosy Health Statistics (2006).

3. National Academy of Social Insurance (2013), USA.

4. Collins JW, Nelson A, Sublet (2006) Safe lifting and movement of nursing home residents. National Institute for Occupational Safety and Health.

5. Nurse Practitioners vs Panel Physicians: A comparison of Worker Compensation Treatment Costs, Henry Intili, FNP.

6. Emory Healthcare among 2015 Top Workplaces in Atlanta. Emory 

(C) Commons Attribution 4.0 License DOI: 10.19080/CTBEB.2017.05.555673

\section{Your next submission with Juniper Publishers will reach you the below assets}

- Quality Editorial service

- Swift Peer Review

- Reprints availability

- E-prints Service

- Manuscript Podcast for convenient understanding

- Global attainment for your research

- Manuscript accessibility in different formats

( Pdf, E-pub, Full Text, Audio)

- Unceasing customer service

Track the below URL for one-step submission https://juniperpublishers.com/online-submission.php 